Portland State University

PDXScholar

1974

\title{
Some correlates of morale among nursing home residents
}

\author{
Gail Olmsted Sydnor \\ Portland State University \\ Patricia Mears Wold \\ Portland State University
}

Follow this and additional works at: https://pdxscholar.library.pdx.edu/open_access_etds

Part of the Gerontology Commons, Social Welfare Commons, and the Social Work Commons Let us know how access to this document benefits you.

\section{Recommended Citation}

Sydnor, Gail Olmsted and Wold, Patricia Mears, "Some correlates of morale among nursing home residents" (1974). Dissertations and Theses. Paper 1767.

https://doi.org/10.15760/etd.1766

This Thesis is brought to you for free and open access. It has been accepted for inclusion in Dissertations and Theses by an authorized administrator of PDXScholar. Please contact us if we can make this document more accessible: pdxscholar@pdx.edu. 
SOME CORRELATES OF MORALE AMONG NURSING HOME RESIDENT'S

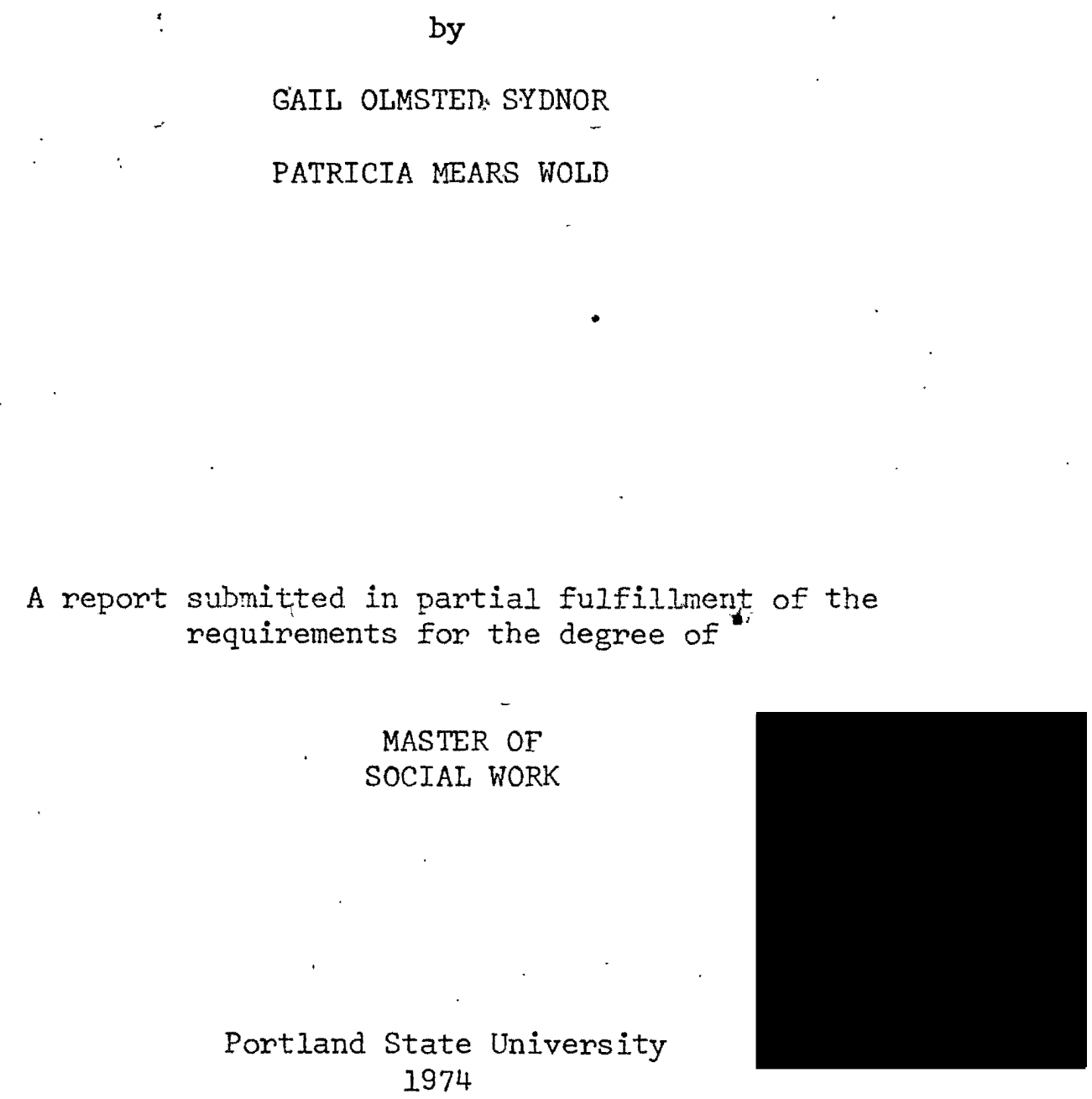


I. Chapter I: The Problem ............. I I Aims. . . . . . . . . . . . . . 1

Rationale for the Study... . . . . . . 2 Assumptions . . . . . . . . . . . 5

Review of the Literature. . . . . . . . . 6

Part I: The Measurement of Morale . . . . 6

Part II: Factors Association with Morale • • 10

Questions to be Explored. . . . . . . . . 19

II. Chapter II: Methodology . . . . . . . 20

Description of the Home . . . . . . . . 20

The Sample. . . . . . . . . . . . 21

Definitions . . . . . . . . . . . . . 23

The Schedule. . . . . . . . . . . 24

The Pretest... . . . . . . . . . . 25

Data Collection and Tabulation. . . . . . . 26

III. Chapter III: Results . . . . . . . . . 29

Analysis and Findings . . . . . . . . . 29

Limitations . . • . . . . . . . . • 32

Implications for Social Work. . . . . . . . 35

Suggestions for Further Research . . . . . . 37 
V. Appendices . . . . . . . . . . . . .

A. Interview schedule. . . . . . . .

B. Eactors on Morale Questions: Orthogonal Factor Matrix (Varimax) . . . . . .

c. Morale Scores for Each Individual ... . 


\section{CHAPTER I: THE PROBLEM}

\section{AIMS}

This is a study of twenty-six patients aged sixty years and over residing in a nursing care facility in Portland, oregon in the fall of 1973, which explores the relationship of their morale and selected environmental and social factors.

There are three major aims of the study. The first is to measure variances in morale states as experienced and reported by the respondents. The second aim is to determine how a given set of factors correlate with the self-reported morale of each of the respondents. Selected for consideration are 1) attitudes: expectations upon entering the home and choice, comparison of one's self-assessed age and health status with that of others, feelings of financial and physical security, feelings of happiness vis $\underline{a}$ vis their life's course; 2) activities: enjoyment of solitary activities, i.e., reading, writing, television, and radio, participation in group activities such as games, crafts, movies, and discussion groups, and visits outside the home; and 3) interpersonal relationships: interaction with peers, the presence or absence of friendships, the frequency of visitors, satisfaction with family relationships, and anticipation of events and contacts with others. The third aim of the study is to identify from the above information, points and strategies for social work intervention. 
RATIONALE

In our predominately youth-centered, future-oriented society, negative stereotypes have traditionally equated old age with uselessness, weakness, decline, infirmity, and death. Little, it has been thought, can be done to reverse the toll that time takes as one inevitably passes into "old age". Consequently, little has been done and many older persons, particularly those in institutions, have been deprived of their right to live in conditions of dignity which we so strongly advocate for the young.

Societal attitudes toward the elderly are grossly reflected in the types and quality of care traditionally available to them in nursing homes. Ralph Nader succinctly described this condition in The Last Segregation:

The most intense focus of what has been wrought for old people is the nursing home. The few homes that are humane, competent, and mindful of their residents' need for activity and meaning in their day highlight the staggering gap between what an affluent society should attain and what is too frequently the reality for most nursing homes. (Townsend, 1971)

Considered by most as a final residence, nursing homes have at best provided only custodial care, confining the patient to bed to last out his life and die. Even the federal government has reversed its token commitment to meet the social-psychological needs of the institutionalized elderly. When the Medicare program went into effect in 1966, it stipulated that nursing homes had to 
provide social services in order to be reimbursed by the government for the care of eligible patients. The Social Security Amendments of 1972 rescinded that stipulation so that at the present time there are no legislative or administrative requirements that make social work services mandatory for the licensing or reimbursement of nursing homes. At best, these services have become optional. Societal attitudes and the consequent dearth of social and restorative services have justified the calling of the nursing home "the last refuge", "the last segregation", "where they go to die".

Much of the gerontological literature has been interpreted in ways which are consistent with and justify the above attitudes. Many different kinds of studies have been made which correlate the various phenomena of aging with inevitable unhappiness, dissatisfaction, and low morale. For example, the tightening constraints of ill-health, increasing economic insecurity and dependency, social isolation; the loss of a spouse and friends, of mobility, and of psychic and physical energy; the restriction of social space in an unfamiliar, often hostile environment, all of which befall the aged in varying degrees, are the antitheses of those factors said to be important in achieving happiness in old age (Lebo, 1953). Thus, based on the realities of institutionalization and of old age, and the seemingly inevitable state of 
unhappiness of the elderly in nursing home, prevailing attitudes of neglect are reinforced.

Fortunately, however, the increasing numbers of older adults have created an increased demand for quality nursing care. The plight of the institutionalized elderly is being exposed, expectations are changing in their behalf, and what were once very negative attitudes are being challenged. New trends in medicine are gradually reversing the old time view that permanent and total disability is the inevitable lot of all nursing home residents. The hopelessness of custodial care is being replaced by a new emphasis on restorative services. Where persons were once sentenced to die in a nursing home, they can now expect to go there to live, in dignity. Moreover, new insights into, and provisions for, meeting the needs of each individual will gradually overturn assumptions that all are necessarily unhappy. Nursing home regulations are being revised; standards are being raised; and the day is forthcoming when resources will be allocated for quality care at every level.

If current trends continue, the social work profession will be pressured into fulfilling its commitment to serve the disadvantaged, regardless of age or health, by assuming its professional responsibility to the institutionalized elderly. While the potential for meeting their social-psychological needs is 
unilmited, chances are that resources will not be. Thus, the question arises of where to begin to intervene, to make a difference, and, in so doing, to substantiate the need for increased allocations and services. Is it true that all are categorically unhappy, or are there varying degrees of morale which can be correlated with one or more identifiable factors?

The present study is based on an effort to explore this question by attempting to find out what does make a difference in self-reported morale of a number of nursing home residents.

\section{ASSUMPTIONS}

The present study is based upon our belief that each individual has a right to attain the highest level of physical, mental, and social functioning possible within his limitations, in order to explore and experience life to its fullest. Within this context, the first underlying assumption is that there is a dimension variously called, happiness, psychological well-being, life satisfaction and morale, and that individuals can be placed relatively high or low on such a dimension.

The second assumption is that the way an individual perceives his well-being or morale influences his physical, mental and social functioning. The third is that an individual's selfimage and social identity emerge, are validated, and are sustained through his interactions with others and with his environment, 
and, therefore, that constraints imposed upon him by his environment adversely influence this image and identity. We further assume that given the knowledge and skills acquired in professional training, social workers can be important agents in improving an individual's self-image and morale.

\section{REVIEW OF THE LITERATURE}

\section{Measurement of Morale}

Various attempts have been made to measure the psychological well-being, alternately referred to as morale, happiness, and adjustment, of Americans in general and in some cases, of older persons in particular. Some have focused attention on the individual's own frame of reference and measured his own evaluation of his well-being, while others have focused on his overt behavior and utilized in their measurements, social criteria of the same dimension. Although none of the measures has been standardized for use with the institutionalized elderly, reference will be made here to those which influenced the construction of the morale scale used in the present study.

Caven, Burgess, Havighurst and Goldhammer (1949) developed two inventories designed to measure adjustment in old age. The activity inventory measures the individual's degree of participation in daily activities common to most people. The attitude 
inventory measures the degree to which a person's attitudes express satisfaction on dissatisfaction with his life situation. The latter contains ten categories which reflect his satisfaction with activities (family, friends, work, recreation, religion, and social organizations), status (health and economic), general happiness, and feelings of usefulness. The total inventory score was obtained by adding together the ten category scores derived from the respondent's answer to each question.

Kutner (1956) constructed a morale scale which is based on the assumption that psychological well-being is a unidimensional phenomenon, that is, it can be measured simply by asking the individual how he feels about himself. Morale refers to a mental state or set of dispositions which can be measured and the most logical source of evaluation, according to Kutner, is the respondent himself. His scale is composed of seven questions, all of which pertain to the individual's feelings about his growing older and his attitudes toward his present life situation; for example, "On the whole, how satisfied would you say you are with your way of life today?", "All in all, how much unhappiness would you say you find in life today?", and "How often do you feel there's just no point in living?"

Researchers Neugarten, Havighurst, and Tobin (1961) attempted to construct a valid measure of the psychological well-being of 
older adults for use in their Kansas City studies, as well as a short, easily administered instrument that could be used in other studies. The finst, which they termed the Life Satisfaction Rating Scale, consists of five separate components: zest, resolution and fortitude, congruence between desired and achieved goals, positive self-concept, and mood tone. Each was rated on a five point scale and the ratings were summed to obtain an overall life satisfaction rating. The ratings based, not on the respondent's direct self-report, but on the inferences drawn by the raters from all the information available to him. Using this scale as a validating criterion, the researchers devised two self-report instruments to be used individually or together. Life Satisfaction Index A consists of twenty agree/disagree items; Index B, of twelve open-ended and check-list questions: four borrowed from Kutner's Morale Scale, others from sources including the Happiness Scale of the Chicago Attitude Inventory (Cavan et al., 1949). For use in their study of the social withdrawal of older persons, Lowenthal and Boler (1965) constructed an "index of morale" which consists of 14 items: 12 open-ended questions and two statements to which the respondent may agree or disagree. Like the Kutner scale, it relies on a direct self-report of the individual's perceived psychological well-being.

In their attempt to assess periodically the social- 
psychological state of the American public, Bradburn and Caplovitz (1965) assumed that there is a dimension variously called mental health, happiness or psychological well-being and that individuals can be described as being relatively high on low on it. To measure an individual's happiness, itself $a_{*}$ "complex resultant of the satisfactions and dissatisfactions, the gratifying and frustrating emotional experiences that occur in a person's life situation" (p. 8), they asked the straightforward question, "Taking all things together, how would you say things are these days--would you say you are very happy, pretty happy, or not too happy?" They considered the answer to this question to be the respondent's best estimate of his present over-all sense of wellbeing or distress. Having administered this question to several different study populations, they found that assessments of such global feelings produce predictable findings with uncommon regularity. The percentage of respondents who said they were "Pretty happy" did not vary significantly with age; that of "very happy" and "not too happy" was inversely proportionate to the age of the respondent. In other words, with increasing age, there was a consistent increase, however slight, in the percentage of persons who said they were "not too happy"--with a proportionate decrease in "very happy" responses. 


\section{Factors Associated With Morale}

The distribution of the above responses on a dimension of self-reported happiness suggests that there are differences in psychological well-being which are not wholly age-related. Moreover, the use of chronological age as a predictor of wellbeing tends to result in a consideration of all elderly persons as a homogeneous group and obscures the complex relationship that exists among physiological, environmental, social, and personal circumstances and individual feelings of well-being. There are factors which are associated with the morale of individuals in similar circumstances, however, which may help to explain morale differences.

The institutionalized elderly have all experienced changes which have a profound effect on their lives. They are subject to conditions over which they have no control. The very fact of their being institutionalized is synonymous with some degree of physical or mental illness and increasing dependency on others for their care. Those who have been employed are no longer working and many experience a consequent loss of economic security and the stimulation and status associated with the work role. Smith and Lipman (1972) used the term constraint to describe the condition of a reduction in monthly income and 
physical capacity which they measured in terms of ability to perform various tasks associated with daily living and the ability to move about or be gainfully employed. Both physical and economic constraints had negative effects on the respondents' reported satisfaction.

In studies' conducted at the Center for Study of Aging and Human Development at Duke University, Busse et al. (1967) found that "the older subject becomes depressed when he cannot find ways of gratifying his needs; that is, when social environmental changes or the decreased efficiency of his body prevent him from reducing his tensions, he is likely to have a loss of self-esteem; hence he feels depressed" (Blank, 1971). "Busse further indicates that when the aging person is studied longitudinally, the importance of physical health becomes even more evident; he can tolerate the loss of love objects and prestige better than a decline in physical health" (p. 386).

The institutionalized elderly are subject to other conditions which may affect thein perception of well-being. Few, if any, chose to be institutionalized; few chose to be isolated, in an often hostile environment, from those people, places and things heretofore so familiar and sustaining, for few would opt to suffer the consequences. Kastenbaum (1972) described the consequences of institutionalization in a way which illustrates the situation 
to which most of the aging patients in a nursing home are exposed.

Each day of exposure to a constricted and ritualized environment (even though it may be this environment that is keeping him alive) tends to reinforce further those regressive or primitivizing processes that age has a way of foisting on us. The aging brain that requires more salient and appealing stimulation receives less--and so, powers of attention and concentration continue to decline; the uprooted citizen who needs appropriate challenges and demands to maintain his sense of interpersonal potency is given few such opportunities or none. It is not surprising that increasingly he comes to resemble the stereotype of apathetic, disconnected old age. Moreover, as the habit and motivation structure of adult life decay the elderly patient finds less and less point in doing anything. Reduction of behavioral output is an invitation to the entire orgamism: physiological processes also slow down. Possessing only the function of being a recipient of medical-nursing-custodial services, the elder eventually may comply by acting as though even his body were no longer his own (p. 369).

The gerontological literature is replete with studies which have attempted to describe factors associated with various morale states of older persons. While few have been conducted among the institutionalized eiderly, they do raise interesting questions which can be explored with this population. Underlying research on social interaction and activity as correlates of morale among the elderly is the implicit assumption that "the social self emerges and is sustained in a most basic way through interaction with others" (Maddox, 1963, p. 203). Moreover, some valued social interaction is essential to the maintenance of positive morale. Few researchers would deny the importance that past life 
experience (i.e., socio-economic status, cultural values, economic and health conditions, structural constraints) have on the relationship between social interaction, activity and morale.

In examining the relationship between types of social activity and life satisfaction among a sample of individuals in a retirement community, Lemon and Bengston (1972) made a distinction between informal, formal, and solitary activities. The first includes social interaction with relatives, friends, and neighbors and is the most interpersonal; while solitary activity is of a non-interpersonal nature. They suggest that activity of an interpersonal nature holds the greatest potential for offering role supports which reaffirm one's self-concept. A positive self-concept is, in turn, associated with high life satisfaction. Their findings did not substantiate the propositions of the activity theory of aging that the greater the frequency of activity per se, the greater one's life satisfaction. They did acknowledge that more activity offered greater opportunity for role supporting interaction.

Lowenthal and Haven (1968) also suggest that the quality or type of interaction rather than the quantity, is an important predictor of life satisfaction. Hypothesizing that the existence of one or more close personal relationships might serve as a buffer against age-linked social losses, they asked 280 community- 
resident aged, "Is there anyone in particular you confide in or talk to about yourself or your problems?" They found the presence of a stable, intimate relationship with a single "confidant" to be positively associated with high morale. However, a confidant does not play a mediating role between physical illness and morale. "The aged person who is...seriously ill is overwhelmingly depressed, regardless of whether or not he has intimate relationships.... One possible explanation is that serious physical illness is usually accompanied by an increase in dependence on others, which in turn may set off a conflict in the ill person more disruptive to his intimate relationships than to more casual ones" (p. 397). Another possible explanation is that illness is accompanied by increased apprehension of death and even in an intimate relationship it is not easy to confess one's fears about the accelerating imminence of death.

Tobin and Neugarten (1961) investigated the hypothesis implicit in the disengagement theory of aging - that there is a positive relationship between disengagement and psychological well-being in the aged. Contrary to their hypotheses, they found that social interaction is positively associated with life satisfaction, and that engagement rather than disengagement is more closely related to psychological well-being.

In his exploratory study of the social relations, recreation- 
al activities and personal adjustment of the residents of a fraternal lodge, Burgess (1954) investigated the relationship of type of activity (solitary, group, spectator, or audience) to reported happiness. He found the most significant difference in group activities, in which those with high happiness scores participated nine times more than those with low scores.

Refuting the notion that the person who "keeps busy" is much happier as he grows older than the person who is idle, Kutner (1956) contends that not any activity but only those that provide status, achievement, and recognition can lift morale.

Not to be overlooked, however, is the possibility that through sheer activity the individual may incidentally find outlets for his feelings or find social relationships that might provide the key to satisfying some of his more fundamental needs. The probability of fortuitously uncovering hidden personal resources or of developing meaningful relationships with others is greater among persons who involve themselves or are drawn into activities than would be the case with the withdrawn or secluded person. (p. 104).

Maddox (1963) tackled the problem of activity as a correlate of morale in a longitudinal study of 182 non-institutionalized subjects sixty years of age and over. He hypothesized that the reported activity of an elderly subject has a positive relationship to his morale. Although he did find that a pronounced increase in reported activity was associated with an increased morale score, the number of deviant cases - slightly more than 
one-in-four - suggested the presence of factors which modified the expected relationship. Maddox introduced three test factors, all of which were found to be significantly related to both activity and morale: first, physical and psychological (e.g., degree of physical disability, self-health estimate, presence or absence of clinical depression, feeling of usefulness); second, social structural (e.g., occupational classification, work role maintenance); and third, type of activity (interpersonal and noninterpersonal). Thus, relatively good health increased the probability that high morale would be found even when activity was low. Moreover, although both interpersonal and non-interpersonal activities contribute to the maintenance of morale, the data alone suggest that high morale is more likely to be associated with high interpersonal and low non-interpersonal than with the alternative combination. This interpretation is complicated by the intervening variable of age which, among the oldest respondents, tends to reverse the relationship.

Maddox and Eisdorfer (1962) attempted to specify the conditions under which the relationship between activity and morale holds in thein analysis of data provided by 250 subjects, aged 60 to 94 . Only limited support could be given to the hypothesis that among the elderly activity decreases as chronological age increases. While "high activity" scores were not 
significantly related to age, they were found to be significantly associated with 1) "good" health; 2) maintenance of work role; 3) stability and control of the living situation; and 4) socioeconomic status. "The data suggest that attention should be shifted from chronological age as an independent variable to the constellation of variables of which age is an index and to variations in the activity-relation characteristics among persons in the same age-range" (p. 258).

Besides the factors of structural, economic, and physical constraints, interaction with others and of activity, two additional factors have been posited as being associated with the morale of older people. One, the expectation of interpersonal pleasure, tends to become one of the major casualties in the transition from community resident to geriatric patient. Kastenbaum (1972) describes several experiments which substantiated his theory that looking forward to an event of some kind of interpersonal pleasure does make a difference in the attitudes and behaviors of institutionalized persons. In one, a social hour was "created" and wine served to the mental patients. Social behaviors, once thought to be irretrievably lost, were re-established among the participants. They became more lively, expressed feeling better about themselves and toward others. Moreover, group interaction increased and continued long after the experi- 
ments ended.

Another study of 34 severely incapacitated male patients who required total care was more intensive and the results dramatic. A ward was redecorated with tables for meals and activities; activity equipment - phonograph, games, puzzles, and bulletin boards - were provided; and beer, cheese, and crackers were served six afternoons a week. Patients wore white shirts and ties every day. After two months the frequency of incontinence
was reduced $50 \%$, the numbers of patients able to walk increased $50 \%$, similar improvement was recorded in participation in individual and group activities, and the use of psychotropic drugs was decreased in amount and kind. In short, it was concluded that there was a marked change in both the morale and behavior of those who had something social to look forward to.

The other, factor associated with morale is the individual's view of himself as compared to others. Kutner (1956) devised a "Self-Image Scale" which consists of three questions designed to measure this view: 1) "Would you say you feel older on younger than most people your age?"; 2) "Do you think your health is better or worse than that of people your age?"; 3) "Would you say it (your standard of living) is better on worse than the standard of living of most of your friends and acquaintances?" An individual's responses to these questions reveal his social 
image. Kutner found a pronounced comelation between self-image and morale in his sample of persons over sixty and concluded that "to regard oneself as disadvantaged or deprived makes for considerable unhappiness" (p. 97).

QUESTIONS TO BE EXPLORED

In this study we will explore the correlation of the level of self reported morale and...

the comparison with peers of perceived age-image.

the comparison with peers on health-status.

the feeling of security regarding care received at the home.

the presence or absence of financial worxy. participation in activities: solitary, recreational or outside the home.

the presence or absence of a confidant.

the anticipation of coming events.

the anticipation of interaction with others.

Interaction with peers.

the number and frequency of visitors.

satisfaction with family relationships. 


\section{CHAPTER II: METHODOLOGY}

\section{DESCRIPTION OF THE HOME}

Our study took place in a corporately owned nursing care facility located in the city of Portland. Licensed by the Oregon State Board of Health for the care of patients requiring both skilled and semi-skilled nursing care as defined by law, it has a capacity of 200 . At the time of the study, approximateIy fourteen beds were occupied by medicare and other patients requiring skilled nursing care. Fifty-five percent of the residents were on welfare with the remaining forty-five percent either subsidized by social security benefits, insurance payments or paying privately for their care.

Although the administrative staff were genuinely concerned about the well-being of residents and sensitive to their diverse needs, their ability to provide adequate services was limited by lack of financial and other resources. Physical therapy and occupational therapy were available only to a few patients for limited periods of time; mental health services were virtually non-existant; and the services of physicians fulfill, for the most part, minimal legal requirements. Limited organized activities, such as games, crafts, and movies, were promoted by a dedicated part-time employee and reached only the relatively well and ambulatory patients. Other activities or diversions 
provided by the community, such as entertainment or religious services, were much appreciated but were not part of any sustained or planned (and therefore dependable) effort.

As a result of the dearth of services available to the residents, the burden not only of their physical care but of their social-psychological needs rests with the poorly-rewarded, relatively untrained but well-meaning aides.

Criteria for choosing this particular home included its urban location, a population large enough to provide an adequate sample size, and diversity in sources of financial support. In addition, its central location, its modern physical plant, and its good reputation indicated that opportunities for interaction and involvement might be available for residents. Finally, and most importantly, selection depended upon the cooperation of the administrator and staff, given unstintingly together with interest and facilitative action.

THE SAMPLE

Our sample was drawn from a population of 133 persons requiring semi-skilled nursing care. It consisted of those aged sixty years and older who were deemed capable, by the two licensed practical nurses in charge, of understanding and responding to the questions. Two of the thirty-three so designated declined participation in the study. In an effort to expand 
the size of the sample and to check for possible conservative bias in selection, four additional residents who appeared interested and alert, were interviewed. Their inability to understand the questions affirmed the researchers' confidence in the above selection process.

The 'interview schedule was administered to thirty-one residents, five of whom were not included in the final sample because of hearing impairment on psychological disturbance which made the reliability of their responses questionable. of the twenty-six respondents in the study sample, fourteen had been admitted to the home from a hospital, five from private residences, one from a home for the aged, and six from other nursing care facilities. All but three reported having no say in the decision to enter the home; only three reported having a possible alternative living arrangement.

Pourteen respondents were women, twelve were men. Three were married, two divorced, thirteen widowed and eight single. They ranged in age from. 61 to 101 with a mean of 77.5 , a median of 77 . Three of the respondents were confined to bed, eight walked without assistance, the remaining 15 relied on the use of a wheelchair.

We were unable to determine how long each resident had lived in a nursing home environment due to insufficient admissions data. 


\section{DEFINITIONS}

Morale refers to a mental state on psychological attitude which is "a complex resultant of the satisfactions and dissatisfactions, the gratifying and the frustrating emotional experiences that occur in a person's life situation" (Bradburn, 1965, p. 8). It can be described in terms of an individual's responses to that situation and to life in general.

Self-reported morale refers to a direct self-report by the individual himself of his own psychological well-being.

Institutionalized elderly refers to those persons who, because of some physical or mental infirmity, are residing in a nursing home where they receive varying degrees of supervisony, nursing and custodial care.

Activity refers to any regularized or patterned action or pursuit which is regarded as beyond routine physical or personal maintenance (Lemon and Bengston, 1972, p. 513). There are many categories of activity including interpersonal and non-interpersonal, formal, informal and solitary.

Perceived age-image refers to that judgment about one's own aging process that an individual makes when he compares himself with the aging process he perceives in others of the same chronological age range. When an individual is asked the question, "Do you feel older or younger than those around you?", his response 
indicates his perceived age-image.

THE SCHEDULE

In order to measure the morale of each of the respondents and to determine which, if any, of a number of selected factors correlate with morale, an interview schedule was constructed and administered face-to-face to each participant in the study. Because of the personal nature of the inquiry and the need for candid, reliable responses, the questions were brief and specific. Every effort was made not to probe, inconvenience, on otherwise disturb the respondents. The time required to administer the interview schedule ranged from fifteen to thirty minutes.

The schedule consisted of three parnts: biographical information obtained from residents and office records, the morale scale, and a series of questions related to factors associated with morale (Appendix A).

The morale scale was designed to measure general morale as directly reported by the respondent. As the researchers were unable to find an instrument appropriate for use with an institutionalized population, they constructed one based on questions drawn from several scales referred to in the review of the literature. It consisted of nine questions selected to elicit feelings of over-all well-being, comparison with others, expectations upon entering the home, and satisfaction with past life 
experiences. Responses to the morale questions were recorded in one of three categories: high, medium, on low.

The third part of the schedule was designed to elicit specific information about attitudes, activities, and social on interpersonal relationships. . Attitudes explored were perceived age-image and health status, worry about lack of money, physical and financial security, and anticipation of future events. Activities were divided into solitary, group and interpersonal, and included any pursuit beyond routine physical or personal maintenance. Interpersonal relationships were those with peers, special friends, outside visitors and family. The choice of questions was based upon research findings reported in the literature which document the association of a variety of factors and morale.

The entire schedule was designed and administered to elicit specific information which required minimal interpretation by the interviewers.

THE PRETEST

Before administering the interview to the sample, the schedule was pretested with. five residents in a different nursing home.

The purpose of the pretest was to familiarize the researchers with the introduction procedure and the instrument, to establish 
uniformity between the interviewers in recording responses, to examine the clarity and scope of the questions, and to discover what effect(s) the inquiry might have on the respondents. Caution was exercised to avoid tiring on otherwise disturbing respondents, and attention pald to the necessity of establishing rapport. of the five residents interviewed, three had had extended contact with one of the two researchers and two had had no prior contact. No difference in response willingness was discerned once understanding of the study's purpose and an interest in participating were acknowledged.

The pretest experience established recording reliability and suggested some modification in the schedule. Two questions were considered inappropriate and deleted. Some rewording improved the comprehension of others. A question was added to elicit information regarding satisfaction with family relationships and a section added for the interviewer's impressions of reliability and for comments about the circumstances of the interview. DATA COLLECTION AND RECORDING

The interviews were conducted in mid-afternoon, the time suggested by the administrator as least disruptive. All data were collected in two weeks. Each respondent was told the purpose of the Inquiry, promised confidentiality, and given the opportunity to choose whether on not he/she wished to participate. 
Responses were scored on individual interview schedules as given, thus eliminating the necessity for recall on the part of the interviewers and allowing for immediate clarification to minimize interpretive judgments.

The responses in the morale section were coded: I for high, 2 for medium, 3 for low. The attitudes, activities and interactions were coded: 1 for yes, 2 for no. Visitor frequency was categorized and coded as follows: 1, no visitors; 2 , one visitor in three months; 3 , one visitor a month; 4,2 on 3 a month; 5 , one visitor per week; 6, 2 or 3 a week; 7, foun or more visitors per week.

Data on family were coded I - if family member(s) lived in the area and the relationship was judged satisfactory by the respondent, 2 - if family resided outside the area yet the relationship was judged satisfactory, 3 - if family were in the area and the relationship was unsatisfactory, 4 - if family were outside the area and the relationship was considered unsatisfactory, 5 - if no family existed.

The coded data were transfermed to IBM cards and verified, for computer processing. A statistical consultant programed the factor analyses of the morale questions, the determination of morale scores for each individual, and the t-tests which measured the association between the mean morale scores and the attitude, 
activity and interaction variables. 
CHAPTER III: RESULTS

ANALYSIS AND FINDINGS

A factor analysis of the responses to the nine morale questions was computed, using an IBM program, for the purpose of determining the underlying commonality and differences among questions. Two factors were identified (Appendix B2. Factor I, a generalized assessment of well-being, incorporated the questions on how happy the respondent was, whether his spirits were high on low, how often he experienced loneliness and despair, how he perceived his happiness vis a vis that of others, and how much unhappiness he found in life today.

Factor II, judgment of past experiences, was composed of only two questions: how satisfied the respondent was with his handling of past situations, and whether life in the nursing home met his expectations. Twelve of the twenty-six respondents in the sample had had no expectations and were unable to answer that question. Because of the weakness of Factor II, it was eliminated from further analysis.

The question "Do you have qualities that make you as good as the people around.you?" was answered medium-affirmative by all, thereby negating its influence and excluding it from both factors. Because of its strength, Factor I was used as the basis for individual morale scores. The responses to the six questions 
included in Factor I were each given weighted values and summed. The mean of these summed responses comprised each.individual's morale score (Appendix C).

On inspection, the distribution of morale scores fell into three clusters. Using -.28 and +.28 as cut off points, seven respondents were classified as having low morale, 10 medium morale and 9 high morale.

Table 1 shows the means, standard deviations and t-test results of the fourteen variables and the morale scores.

As Table 1 illustrates, differences in the variables perceived age-image and health status, the presence or absence of a confidant, money matters, solitary activities and anticipating events, were not significantly associated with the morale scores. With the exception of a confidant, these variables are all noninterpersonal in nature. Security regarding the care received Is the only non-interpersonal variable with significant influence on morale. All the others involve interpersonal interaction. This is in accord with the findings reviewed that stressed the importance of interpersonal activity in maintaining morale.

Although this study was designed to establish the correlation between singular factors and morale, worth noting is the correspondence between morale scores and the cumulative number of positivé and negative responses over all fourteen variables. 
Table 1

Test of Association Between Morale Scores and Selected Variables

\begin{tabular}{|c|c|c|c|c|c|}
\hline Variable & & n. & Mean & S.D. & $t:$ \\
\hline $\begin{array}{c}\text { Healthier } \\
.\end{array}$ & $\begin{array}{l}\text { yes } \\
\text { no }\end{array}$ & $\begin{array}{l}13 \\
12\end{array}$ & $\begin{array}{l}.1829 \\
.1133\end{array}$ & $\begin{array}{l}.1050 \\
.7901\end{array}$ & .7913 \\
\hline Younger & $\begin{array}{l}\text { yes } \\
\text { no }\end{array}$ & $\begin{array}{r}17 \\
8\end{array}$ & $\begin{array}{l}.4182 \\
.3830\end{array}$ & $\begin{array}{l}.1025 \\
.7403\end{array}$ & .0086 \\
\hline Confidant & $\begin{array}{l}\text { yes } \\
\text { no }\end{array}$ & $\begin{array}{l}12 \\
14\end{array}$ & $\begin{array}{l}.2810 \\
.2413\end{array}$ & $\begin{array}{l}.9360 \\
.9650\end{array}$ & .0013 \\
\hline Anticipate Events & $\begin{array}{l}\text { yes } \\
\text { no }\end{array}$ & $\begin{array}{r}4 \\
22\end{array}$ & $\begin{array}{l}.1561 \\
.2838\end{array}$ & $\begin{array}{l}.1306 \\
.8866\end{array}$ & .3575 \\
\hline Anticipate People & $\begin{array}{l}\text { yes } \\
\text { no }\end{array}$ & $\begin{array}{r}18 \\
8\end{array}$ & $\begin{array}{l}.3162 \\
.7116\end{array}$ & $\begin{array}{l}.7269 \\
.9935\end{array}$ & $2.9728 *$ \\
\hline Care Security & $\begin{array}{l}\text { yes } \\
\text { no }\end{array}$ & $\begin{array}{l}16 \\
10\end{array}$ & $\begin{array}{l}.4160 \\
.6656\end{array}$ & $\begin{array}{l}.7450 \\
.8313\end{array}$ & $3.446 *$ \\
\hline Financial Worry & $\begin{array}{l}\text { yes } \\
\text { no }\end{array}$ & $\begin{array}{r}4 \\
22\end{array}$ & $\begin{array}{l}.7394 \\
.1344\end{array}$ & $\begin{array}{l}.1113 \\
.8575\end{array}$ & 1.799 \\
\hline Spending Money & $\begin{array}{l}\text { yes } \\
\text { no }\end{array}$ & $\begin{array}{r}16 \\
9\end{array}$ & $\begin{array}{l}.1982 \\
.2023\end{array}$ & $\begin{array}{l}.8927 \\
.9333\end{array}$ & 1.060 \\
\hline Solitary Activity & $\begin{array}{l}\text { yes } \\
\text { no }\end{array}$ & $\begin{array}{r}19 \\
7\end{array}$ & $\begin{array}{l}.1823 \\
.6078\end{array}$ & $\begin{array}{l}.7911 \\
.1180\end{array}$ & 1.914 \\
\hline Peer Activity & $\begin{array}{l}\text { yes } \\
\text { no }\end{array}$ & $\begin{array}{l}12 \\
14\end{array}$ & $\begin{array}{l}.4570 \\
.4420\end{array}$ & $\begin{array}{l}.5706 \\
.1042\end{array}$ & $2.5472 \%$ \\
\hline Recreation & $\begin{array}{l}\text { yes } \\
\text { no }\end{array}$ & $\begin{array}{r}6 \\
20\end{array}$ & $\begin{array}{l}.8507 \\
.1811\end{array}$ & $\begin{array}{l}.4293 \\
.8130\end{array}$ & $2.898 *$ \\
\hline Going Outside & $\begin{array}{l}\text { yes } \\
\text { no }\end{array}$ & $\begin{array}{l}12 \\
14\end{array}$ & $\begin{array}{l}.5565 \\
.4792\end{array}$ & $\begin{array}{l}.5452 \\
.9399\end{array}$ & $3.357 \%$ \\
\hline Visitors Monthly & $\begin{array}{l}\text { yes } \\
\text { no }\end{array}$ & $\begin{array}{r}21 \\
5\end{array}$ & $\begin{array}{l}.2224 \\
.9403\end{array}$ & $\begin{array}{l}.8200 \\
.8332\end{array}$ & $2.8417 *$ \\
\hline Pamily Satisfaction & $\begin{array}{l}\text { yes } \\
\text { no }\end{array}$ & $\begin{array}{r}17 \\
9\end{array}$ & $\begin{array}{l}.3724 \\
.7069\end{array}$ & $\begin{array}{l}.6665 \\
.9825\end{array}$ & $3.330 *$ \\
\hline
\end{tabular}

$* \mathrm{p}<.01$, two tailed 
Those categorized as having high morale averaged positive responses on 10.6 variables and negative responses on 3.4 variables. The average for the moderately happy was 8.2 positive and 5.8 negative. The low morale group averaged 4.7 positive responses and 9.3 negative. Satisfaction or frustration -in one area may not be as important as the number and kind of areas satisfied or frustrated.

In summary, the major findings are:

1. Engagement in activities of an interpersonal nature are positively associated with morale.

2. The security that the institutionalized elderly feel regarding the care they receive is positively associated with morale.

3. The greater the number of variables satisfied, the higher the morale.

4. Anticipation of contact with friends and relatives has an important influence on the maintenance of morale.

5. Self-reported happiness is positively associated with the level of morale.

$$
\text { LIMITATIONS . }
$$

- An in-depth review of the literature revealed no research with a population of institutionalized elderly upon which this study could be based. As a consequence, ideas were borrowed from 
a number of less-suitable gerontological studies and an attempt made to construct an exploratory study which would have some implications for the social work profession.

The size of the sample was smaller than had been intended. The researchers chose the nursing home on the basis of its relatively large capacity in the hope of being able to obtain a sample of at least 35 . Only 26 could be included, however, due to the condition of most of the residents and the nature of our inquiry. As the kinds of activities and opportunities for interaction vary considerably from one home to another, no attempt was made to expand the sample size by going into additional facilities. By the same token, findings of this study should be applied with care as settings and populations differ.

The researchers relied solely on the direct self-reports of the respondents for their information. No attempt was made to validate either by cross-checking with others or by observation. The resulting data were consequently vulnerable to the respondent's motives, his memory, his reactions to the schedule, and to the circumstances of the interview. Untested were such variables as the time of day, mood, and conscious and unconscious psychological defenses.

Moreover, the nature of the questioning process most likely had an effect on the information obtained. For the purpose of 
this study and because of the potential consequences of doing otherwise, the subjects were restricted by the researchers' insistence on direct answers. For the most part, only fixed alternatives were made available, and in the case of the few more- open-ended questions, every effort was made to obtain specific information.

Although the focus of the investigation was on selected factors hypothesized to be associated with morale, there may be complex intervening variables which might influence the perceived well-being of each respondent such as past life experiences, sociomeconomic status, personality and circumstances of admission to the home. At any given time, the self-reported morale of a nursing home resident might also be influenced by the kind and amount of medication he is on as well as the attitudes of the staff toward him. Chances are that some patients are given more attention and encouragement than others and that some are expected to participate in their own care and in activities while others are expected to be more passive.

A further limitation is inherent in the very nature of the study. Essentially an effort to establish the degree of association between morale and selected variables, no attempt was made to examine cause and effect relationships. Throughout the study every effort was made not to confuse, in any way, a causal 
relationship between morale and selected factors with a corelationship.

Another limitation is that many research studies in the field could not be reviewed in the time available, and many more studies will continue to appear throwing new and different light on the problems associated with morale and well-being.

One should keep in mind the selecting criteria and characteristics of the sample, a select and not a random sample. One should also not forget those who could not respond - their morale and its correlates.

IMPIICATIONS FOR SOCIAL WORK

Variations in the reported morale of the respondents was recorded and a significant degree of association was found between level of morale and interpersonal kinds of activities, care security, and going outside of the home. Although the presence of these factors was highly associated with morale, there was some discrepancy among respondents. Absence of satisfactory family relationships or care security, for example, might have been offset by the presence of other satisfactions. Thus, all respondents seemed to profit from the opportunity for interaction, but not necessarily interpersonal opportunities of the same kind or amount.

Implied in the above is a challenge to social workers to 
intervene on behalf of the institutionalized elderly in ways which will make a difference to each as an individual. Rather than assume, for example, that the lack of interaction is a desirable or conscious choice on the part of the individual, the social worker must be a spokesman for his social-psychological needs.' Not only must the social worker advocate opportunities for interpersonal activities, but she must create situations conducive to interaction and see to it that each individual may participate in those most meaningful to him. In many cases, this will entail the training of some nursing home staff so that they will be able to address themselves to the social needs of their patients. Consultation with staff members about social-psychological problems and individual treatment plans may also be required.

Consistent with the workers' role of advocate, change agent, and staff developer are several further tasks. First, the taking of social histories to determine which aspects of a patient's life are frustrated and need attention as well as identifying persons in his life who are potential participants in his care. Second, the maintaining of contact with significant others in the patient's life, not merely "next of kin", so as to encourage relationships of an interpersonal nature. Third, the enlisting of community support to provide opportunities for activities 
within the home and visits outside the home, thus adding a new dimension to an otherwise restricted social space.

On a broader scale, social workers must advocate for new licensing standards which would require the availability of social services to all nursing home patients as well as make those services possible through increased subsidies. Moreover, they must be instrumental in the changing of attitudes towards the institutionalized elderly and in making their needs known to those who can help to satisfy them.

\section{SUGGESTIONS FOR FURTHER RESEARCH}

The potential and possibilities for further study among the institutionalized aged are unlimited. A population heretofore too often ignored in the field of gerontological, social work research, it will inevitably demand increasing attention as its size increases in number and visibility. Moreover, as the needs of the elderly in nursing homes are recognized, more pressure will be exerted on all concerned from the local to the national level, to meet. those needs.

Several suggestions for further research can be drawn from the present study. First, using the same schedule, the sample size and sample units could be significantly increased. Not only would this provide an opportunity to compare the demographic variables of age, sex, marital status, length of residence, and 
history of past institutionalization of the respondents with their reported morale, it would also verify the results. Second, and again using the same or a similar schedule, the study could be conducted simultaneously in two or more homes. As the latter differ in the kinds of services, activities, and opportunities available, as well as in the attitudes of administrators and staff toward the elderly, a study of this kind could examine the effect of these variables on morale.

An experiment could also be designed in which the sample would be divided into a test group and a control group. To the former, opportunities of various kinds could be offered: activities, visits outside the home, happy hours, visitors, or remodelled sumroundings. To the latter group, no new stimulus would be available. A morale scale would be administered before the beginning of the experiment to both groups, and then at predetermined intervals to determine the effects of certain factors on morale.

Research designed to answer the question of what makes a difference, measured in terms of self-reported morale, to nursing home residents aged sixty years and over, might be conducted in the area of the effects of institutionalization. Still further studies could examine causal relationships to begin to pinpoint some of the critical determinants of morale 
of this population. These and other research efforts are crucial to understanding the complex phenomenon of perceived wellbeing or morale. Through them some direction might be gained in the efforts of those in the helping professions to utilize limited resources in the most effective and comprehensive ways. 


\section{BIBLIOGRAPHY}

Adams, David L. "Analysis of a Life Satisfaction Index," Journal of Gerontology, Vol. 24, No. 4, October, 1969, 470-474.

Beard, Belle Boone. Social Competence of Centenarians. Atlanta: University of Georgia Printing Dep't, 1967.

Blank, Marie L. "Recent Research Findings on Practice with the Aging," Social Casework, Vol. 52, No. 6, June, 1971, 382-389.

Boehm, Wermer W. The Plan for the Social Work Curriculum Study. Council of Social Work Education, Document 6-70-12, August, 1956.

Bradburn, N., and Caplovitz, D. Reports on Happiness. Chicago: Aldine Publishers, 1965.

Burger, Robert E. "Who Cares for the Aged," Saturday Review, Vol. 52, January 25, 1969, 14-17.

Burgess, E. W. "Social Relations, Activities, and Personal Adjustment," American Journal of Sociology, Vol. 59, No. 4, January, $1954,352-360$.

Cavan, Ruth, et al. Personal Adjustment in Old Age. Chicago: Science Research Associates, 1949.

Eisdorfer, Carl. "The Implications of Research for Medical Practice," The Gerontologist, Vol. 10, No. I, Spring, 1970, 6267.

Ford, Malcolm. "Today's Problems and Needs in the Nursing Home Field," Nursing Homes, Vol. 7, No. 6, June, 1958, 193-194.

Gurin, G., Veroff,.J., and Feld, S. Americans View Their Mental Health. New York: Basic Books, 1960 .

Havighurst, R. J. "Successful Aging," in Gerontology, A Book of Readings. Edited by C. B. Vedder, Springfield, Illinois: C. C. Thomas, $1963,66-78$.

Havighurst, R. J., Neugarten, B. L., and Tobin, S. S. "Disengagement and Patterns of Aging," in Middle Age and Aging. Edited by B. L. Neugarten, Chicago: University of Chicago Press, 1968, 16I172 . 
Jetters, F. and Nichols, C. "The Relationship of Activities and Attitudes to Physical Well-Being in Older People," Journal of Gerontology, Vol. 16, No. 1, January, 1961, 67-70.

Kosberg, Jordan J. "The Nursing Home: A Social Work Paradox," Social Work, Vol. 18, No. 2, March, 1973, 105-110.

Lebo, Dell. "Some Factors Said to Make for Happiness in Old Age," Journal of Clinical Psychology, Vol. 9, No. 4, October, 1953, 384-390.

Lemon, B. W., Bengston, V. L., and Peterson, J. A. "An Exploration of the Activity Theory of Aging: Activity Types and Life Satisfaction Among In-Movers to a Retirement Community," Journal of Gerontology, Vol. 27, No. 4, October, 1972, 511-523.

Lieberman, Morton A. "Institutionalization of the Aged: Effects on Behavior," Journal of Gerontology, Vol. 24, No. 3, July, 1969, $330-340$.

Lieberman, Morton A. and Lakin, Martin. "On Becoming an Institutionalized Person," in Processes of Aging, Social and Psychological Perspectives, Vol. I. Edited by Williams, Tibbets, and Donahue, New York: Atherton Press, 1963, 475-503.

Lowenthal, M. F. and Bolar, D. "Voluntary vs. Involuntary Social Withdrawal," Journal of Gerontology, Vol. 20, No. 3, July, 1965, 363-371.

Lowenthal, M. F. and Haven, Clayton. "Interaction and Adaptation: Intimacy as a Critical Variable," in Middle Age and Aging.

Edited by B. L. Neugarten, Chicago: University of Chicago Press, $1968,390-400$.

Maddox, Geroge L. "Activity and Morale: A Longitudinal Study of Selected Elderly Subjects," Social Forces, Vol. 42, No. 2, December, 1963, 195-204.

Maddox, George L. "Persistence of Life Style Among the Elderly: A Longitudinal Study of Patterns of Social Activity in Relation to Life Satisfaction," in Middle Age and Aging. Edited by B. L. Neugarten, Chicago: University of Chicago Press, 1968, 181-183.

Maddox, George L, and Eisdorfer, Carl. "Some Correlates of Activity and Morale Among the Elderly," Social Forces, Vol. 40, No. 3, March, 1962, 254-260. 
Robinson, John P. and Shaver, Phillip R. Measures of Social-Psychological Attitudes. Ann Arbor: Institute for Social Research, University of Michigan, 1969.

Rose, Amold. "A Current Theoretical Issue in Social Gerontology," in Middle Age and Aging. Edited by B. L. Neugartan, Chicago: University of Chicago Press, 1968, 184-189.

Scott, F. G. "Factors in the Personal Adjustment of Institutionalized and Non-Institutionalized Aged," American Sociological Review, Vol. 20 , No. 5 ; October, $1955,538-546$.

Smith, Kenneth and Lepman, Aaron. "Constraint and Life Satisfaction," Journal of Gerontology, Vol. 27, No. 1, January, 1972, 77-82.

. Tobin, Sheldon S, and Neugartan, Bernice L. "Life Satisfaction and Interaction in the Aging," Journal of Gerontology, Vol. 16, No: 4, October, 1961, 344-346.

- Townsend, Claire. Old Age: The Last Segregation. New York: Grossman Publishers, 1971.

Townsend, Peter. The Last Refuge. London: Routledge Kegan, 1964. 
APPENDICES 
APPENDIX A

INTERVIEW SCHEDULE

Room: Age: - Sex: Marital: Degree Ambulation:

Length of Residence:

Admission circumstances:

Existing alternatives:

MORALE

High Med. Low

1. Taking all things together, how would you say things are these days? Would you say you're very happy, pretty happy, or not too happy?

2. Looking back upon your life and the situations you found yourself in, how satisfied are you with the way you handied them?

3. How often do you feel there's just no point in living?

4. Compared to others around you, how happy would you say you are?

5. All in all, how much unhappiness would you say you find in life today?

6. In general, how would you say you feel most of the time... in good spinits on low?

7. All things considered, would you say things seem to be better or worse than you thought they would be when you came here?

8. Do you have qualities that make you as good as the people around you? (How do you feel about yourself?)

9. How often would you say you are lonely? When you are, what comforts you? 


\section{CORRELATES OF MORALE}

1. Do you feel healthier than those around you?

2. Do you feel younger than those around you?

3. Is there a special person that you're close to--with whom you can share your thoughts, feelings, and fears?
a) number: :
b) relationship:
c) frequency of contact:

4. Is something going to happen in the near future that you are looking forward to?

5. Are there other people you look forward to seeing in the near future?

6. Do you feel secure regarding the care you receive? If not, why not?

7. Do you worry about your financial situation?

8. Do you have enough money for what you want or need? If not, who provides for you?

9. What do you do to fill youn time?
a) solitary activities:
b) activities with others in the home:
c) visitors:
d) visits outside the home:

10. Have you family in the area?
a) How often are you in contact with them?
b) Have you other relatives you correspond with?
c) Would you say your family relationships are satisfying or good?


NOTES

Judged frame of mind:

Reliability:

Did respondent seem comfortable?

Other circumstances: 


\section{APPENDIX B}

FACTORS ON MORALE QUESTIONS:

ORTHOGONAL FACTOR MATRIX (VARIMAX)

$\begin{array}{ccc}\text { Question No. } & \text { Factor I. } & \text { Factor II } \\ 1: & 0.7958 & 0.3136 \\ 2 & 0.4744 & 0.7382 \\ 3 & 0.7605 & 0.1213 \\ 4 & 0.7537 & 0.1425 \\ 5 & 0.8438 & 0.1528 \\ 6 & 0.8491 & 0.0784 \\ 7 & 0.2831 & 0.8530 \\ 8 & 0.0000 & 0.0000 \\ 9 & 0.5913 & 0.0641\end{array}$




\section{APPENDIX C}

MORALE SCORES FOR EACH INDIVIDUAL

$\begin{array}{cc}\text { Person } & \text { Factor I } \\ 1 & 0.68668 \\ 2 & 0.91741 \\ 3 & 0.02321 \\ 4 & 0.18285 \\ 5 & -0.49711 \\ 6 & 0.91741 \\ 7 & -0.12712 \\ 8 & -1.1746 \\ 9 & 1.1251 \\ 10 & -1.6202 \\ 11 & 0.06476 \\ 12 & -0.16760 \\ 13 & -1.6202 \\ 14 & 1.10300 \\ 15 & -1.0174 \\ 16 & -0.0320 \\ 17 & 0.97483 \\ 18 & -0.12712 \\ 19 & 0.26227 \\ 20 & 1.1515 \\ 21 & 0.00289 \\ 22 & 1.0300 \\ 23 & 0.87750 \\ 24 & -1.3509 \\ 25 & -1.7826 \\ 26 & 0.2708\end{array}$

